\title{
Experimental Investigations on a Novel Chemical Looping Combustion Configuration
}

\author{
M.M. Yazdanpanah ${ }^{1 *}$, A. Hoteit ${ }^{1}$, A. Forret ${ }^{1}$, A. Delebarre ${ }^{2}$ and T. Gauthier ${ }^{1}$ \\ 1 IFP Energies nouvelles, Rond-point de l'échangeur de Solaize, BP 3, 69360 Solaize - France \\ 2 ESSTIN, Université Henri Poincaré, Nancy - France \\ e-mail: mohammad-mahdi.yazdanpanah@ifpen.fr - ali.hotei†@ifpen.fr - ann.forret@ifpen.fr \\ arnaud.delebarre@esstin.uhp-nancy.fr - thierry.gauthier@ifpen.fr \\ * Corresponding author
}

Résumé - Étude expérimentale d'une nouvelle configuration de combustion en boucle chimique - La combustion en boucle chimique (CLC) est une nouvelle technologie prometteuse qui implique la séparation inhérente du dioxyde de carbone avec une perte minimale d'énergie. Un transporteur d'oxygène est utilisé pour le transfert de l'oxygène en continu du "réacteur air" vers le "réacteur fioul" où l'oxygène est apporté au combustible. Ainsi, le contact direct entre l'air et le combustible est évité. Le gaz résultant est riche en $\mathrm{CO}_{2}$ et n'est pas dilué avec de l'azote. Le transporteur d'oxygène réduit est ensuite transporté vers le réacteur air afin d'être ré-oxydé, formant ainsi une boucle chimique.

Diverses configurations CLC ont déjà été développées et testées à l'échelle laboratoire. Cependant, des travaux de recherche supplémentaires sont nécessaires pour garantir la faisabilité du procédé. Parmi les différents points à aborder, le contrôle du débit de circulation du solide entre les deux réacteurs est de la plus haute importance, notamment en ce qui concerne son impact sur l'apport en oxygène et le degré d'oxydation du solide. Aussi la réduction des fuites de gaz entre le réacteur fioul et le réacteur air est un autre point important à prendre en considération. Dans cette étude, une nouvelle configuration de CLC est proposée où les réactions sont effectuées dans deux lits fluidisés bouillonnants interconnectés. Le contrôle du débit de circulation du solide est réalisé indépendamment du débit de gaz de fluidisation des réacteurs en utilisant des vannes pneumatiques non-mécaniques. Les siphons sont également employés pour réduire au mieux les fuites de gaz lors du transfert solide.

Les résultats expérimentaux obtenus dans une maquette froide équivalente à un pilote de $10 \mathrm{kWth}$ sont présentés dans ce travail. L'impact des paramètres opératoires sur le taux de circulation du solide, des fuites de gaz entre les deux lits et l'équilibre des pressions sur l'ensemble des éléments du système est étudié. Une circulation stable du solide a été obtenue grâce à un contrôle maîtrisé du débit du solide et une étanchéité efficace du système.

\footnotetext{
Abstract - Experimental Investigations on a Novel Chemical Looping Combustion Configuration Chemical Looping Combustion (CLC) is a promising novel combustion technology involving inherent separation of carbon dioxide with minimum energy penalty. An oxygen carrier is employed to continuously transfer oxygen from the air reactor to the fuel reactor where the oxygen is delivered to the fuel. Consequently, direct contact between the air and fuel is prevented. The resulting flue gas is $\mathrm{CO}_{2}$-rich, without $\mathrm{N}_{2}$ dilution. The reduced oxygen carrier is then transported back to the air reactor for re-oxidation purposes, hence forming a chemical loop.

Various CLC configurations have already been developed and tested on laboratory scales. However, more investigations are required to achieve feasible CLC processes. Among the different points to
} 
address, control of the solid circulation rate between the two reactors is of the highest importance regarding its effect on achievement of an appropriate oxygen transfer rate and solid oxidation degrees. Moreover, minimization of gas leakage between the fuel and air reactors is another important issue to be considered. A novel CLC configuration is proposed where reactions are carried out in two interconnected bubbling fluidized beds. Solid circulation rate control is achieved independently of gas flow rate in the reactors through use of pneumatic non-mechanical valves (L-valves). Moreover, loopseals are employed to minimize gas leakage while transferring solids.

Experimental results from operation of a $10 \mathrm{~kW}_{\text {th }}$ equivalent cold prototype are presented in this paper. The effect of operating variables on the solid circulation rate, gas leakage between the two beds and the pressure balance on all of the process elements is studied. The results demonstrate stable solid circulation with efficient control of the solid flow rate and effective gas tightness of the system.

\section{NOMENCLATURE}

\section{Symbols}

A Area of reactor $\left(\mathrm{m}^{2}\right)$

CLC Chemical Looping Combustion

$D_{p} \quad$ Pipe diameter (m)

$d_{p} \quad$ Solid particle size $(\mathrm{m})$

FCC Fluid Catalytic Cracking

$f_{g} \quad$ Friction factor of gas flow

$f_{s} \quad$ Friction factor of solid flow

$G_{s} \quad$ Solid flux $\left(\mathrm{kg} / \mathrm{m}^{2} . \mathrm{s}\right)$

$H_{R} \quad$ Solid height in the reactor (m)

$M \quad$ Mass of solid inventory $(\mathrm{kg})$

$Q \quad$ Gas flow rate $\left(\mathrm{Nm}^{3} / \mathrm{h}\right)$

$Q_{S s} \quad$ Aeration below the supply chamber of the loop-seal $\left(\mathrm{Nm}^{3} / \mathrm{h}\right)$

$Q_{S r} \quad$ Aeration below the recycle pipe of the loop-seal $\left(\mathrm{Nm}^{3} / \mathrm{h}\right)$

$t \quad$ Time (s)

$U \quad$ Superficial velocity $(\mathrm{m} / \mathrm{s})$

$v \quad$ Interstitial velocity $(\mathrm{m} / \mathrm{s})$

$W_{s} \quad$ Solid flow rate $(\mathrm{kg} / \mathrm{h})$

\section{Greek symbols}

$\mu_{\mathrm{f}} \quad$ Fluid viscosity (Pa.s)

$\delta \quad$ Gas fraction ratio in the L-valve

$\varepsilon \quad$ Voidage of the bed

$\varepsilon_{\mathrm{s}} \quad$ Free settled bed voidage

$\varepsilon_{\mathrm{st}} \quad$ Forced settled bed voidage

$\rho \quad$ Density $\left(\mathrm{kg} / \mathrm{m}^{3}\right)$

$\phi \quad$ Sphericity of solid particles

\section{Subscripts}

acc Acceleration pressure drop $(\mathrm{Pa})$

Cyc Cyclone
Cyc,s Solid exit of cyclone

$D R$ Solid in the reactor above entrance of the loop-seal

$f \quad$ Fluid

G Gas

$H C$ Horizontal pneumatic conveying line

$H P$ Horizontal Pipe of the loop-seal

$L \quad$ Lift (riser)

ls Loop-seal

$L v, v \quad$ Standpipe of the L-valve

$o \quad$ Outlet exit Contraction in cyclone

piping Discharge line of cyclone to atmosphere

$R \quad$ Reactor

$r \quad$ Relative

$r g \quad$ Gas Reversal

$R P \quad$ Recycle Pipe of the loop-seal

$R C \quad$ Recycle Chamber of the loop-seal

$S \quad$ Solid particles

SC Supply Chamber of the loop-seal

$\mathrm{Tb}$ Blinded tee bent

\section{INTRODUCTION}

Carbon Capture and Storage (CCS) is considered as a midterm solution to reduce greenhouse gas emissions [1]. The cost of $\mathrm{CO}_{2}$ capture is, however, one of the major challenges facing CCS. Chemical Looping Combustion (CLC), an indirect combustion process, has the advantage of being one of the most cost-efficient processes for $\mathrm{CO}_{2}$ capture [2, 3]. CLC employs an intermediate oxygen carrier, mostly metal oxide, to continuously transfer air oxygen from the Air Reactor (AR) to the Fuel combustion Reactor (FR). The overall reaction heat of the process is the same as a conventional combustion process. The resulting flue gas is rich in $\mathrm{CO}_{2}$ diluted with water vapor which can be easily condensed out of the stream. The separation energy penalty is therefore minimum, making CLC a promising route for $\mathrm{CO}_{2}$ separation.

Chemical Looping Combustion was first suggested by Richter [4] to increase efficiency of the combustion reaction 
through reduction of irreversible entropy production. Since then, mostly in recent years, much research [5-13] has been devoted to development of CLC process for the aim of $\mathrm{CO}_{2}$ capturing. Various designs have already been proposed for the CLC process. These can be classified into two general categories, interconnected fluidized bed designs and fixed bed processes. In the first category, the most common design is based on the conventional Circulating Fluidized Bed (CFB) systems with addition of a second reactor as the Fuel Reactor [14-16]. In these systems a low velocity bubbling fluidized bed reactor is devoted to the fuel combustion reaction and a high velocity riser is considered as the Air Reactor. The advantage of this design is the fact that due to its similarity with conventional CFB combustion processes, it is well adopted with existing power generation units and its phenomena have been the subject of many investigations to date. However, in this design, solid flow between the two reactors $[17,18]$ is a function of the gas flow and solid inventory in each reactor. In other words, solid flow cannot be adjusted independently of other parameters of fluidization. To improve solid circulation control and achieve proper residence time in the reactors different modified designs have been developed. Forero et al. [5] have added a bubbling fluidized bed as the Air Reactor (AR) just below the riser. De Diego et al. [6] have also used a bubbling fluidized bed as the AR while separating the riser and the AR using a loopseal. Kolbitsch et al. [7] have developed the concept of a Dual Circulating Fluidized Bed (DCFB) where the Fuel Reactor is operated in a turbulent regime forming a second loop inside the overall system. They accordingly succeeded in controlling the solid flow rate just based on the aeration rate in the AR, independent of the gas rate in the FR. Kronberger et al. [8] have developed an alternative design, a two-compartment fluidized bed reactor, with a simplified configuration resulting in smaller installation requirements and lower cost. Son et al. [9] have proposed an annular fluidized bed CLC reactor in order to provide sufficient reaction time and optimize heat transfer between the reactors. Alstom Power Inc. [10] has developed a novel system based on calcium sulfide which includes an additional cycle of calcinations. Fixed bed designs have also been proposed such as a packed bed CLC [11], packed bed membrane-assisted chemical looping reactor [12] and rotating bed reactor [13].

IFP Energies nouvelles and TOTAL have started a R\&D collaboration project on CLC. As part of the project, a novel design based on interconnected bubbling fluidized beds was developed at IFP Energie nouvelles to build a $10 \mathrm{~kW}_{\text {th }}$ pilot plant. The main concern was to insure an independent solid flow control, and to achieve reduced gas leakages between the Air Reactor and Fuel Reactor. A cold prototype was constructed with similar geometrical dimensions to the hot CLC prototype. This paper presents experimental results on operation of the cold prototype, on solid circulation and loop-seal stability.

\section{DESIGN}

Chemical Looping Combustion relies on the circulation of oxygen carriers between the Air Reactor and Fuel Reactor. Proper selection of the oxygen carrier and a solid circulation rate are essential criteria to meet CLC process performances. Adjustment of the solid flow rate depends mostly on the intrinsic properties of the oxygen carrier in oxygen transfer, the thermal behaviour of the system, and the fuel feeding rate. Solid circulation may bring about undesirable gas leakage between the reactors, causing a dilution of the $\mathrm{CO}_{2}$ stream and reduction of $\mathrm{CO}_{2}$ separation efficiency. Accordingly, control of gas leakage is another important parameter in the CLC process. Moreover, operational flexibility, which can be achieved through flexible solid and gas flow control, is of great interest, especially in laboratory-scale operations. This permits the use of different oxygen carriers, various feeds and a flexible energy production rate.

Solid circulation control can be best achieved through use of mechanical valves, as in some mature catalytic processes such as Fluid Catalytic Cracking (FCC) [19]. High temperature, however, limits the use of mechanical valves for CLC applications. Therefore, in the current design non-mechanical L-valves are used.

The process design developed by IFP Energies nouvelles to study CLC on the pilot scale is represented in Figure 1. The aim of the current study was to investigate the operation feasibility of the developed design and develop a proper understanding of solid circulation and possible operational limits in cold flow conditions. Moreover, the results permit development of a model to predict operation in the high temperature conditions of a real CLC pilot plant. The prototype is composed of two interconnected bubbling fluidized bed reactors, R1 and R2, with a circular cross-section of $0.1 \mathrm{~m}$ and height of $1 \mathrm{~m}$. Bubbling beds are used to ensure sufficient contact time between the solid and gas/air to achieve optimum reaction conversion. Besides, this will result in higher flexibility of the system and permits use of various oxygen carriers with different oxidation and reduction reaction rates. Gases are injected at the bottom of the reactors through staggered perforated plates. The reactors' cross-section increases at the top in order to reduce gas velocity and trap part of the entrained solids back into the reactor. Pneumatic L-valves are used to control the solid flow rate. High temperature operation requires use of thermal insulation around the reactors and solid transport lines. This in turn imposes a minimum horizontal distance between each reactor and corresponding vertical pneumatic transport line (R1/R2 and L1/L2 in Fig. 1). Solids should then be transported through this horizontal distance via L-valves. Stable solid flow in the L-valves, however, limits the maximum length of the horizontal section. Therefore, hybrid standpipes were used in the L-valves with an inclined section to convey solids horizontally while keeping the length of the horizontal 


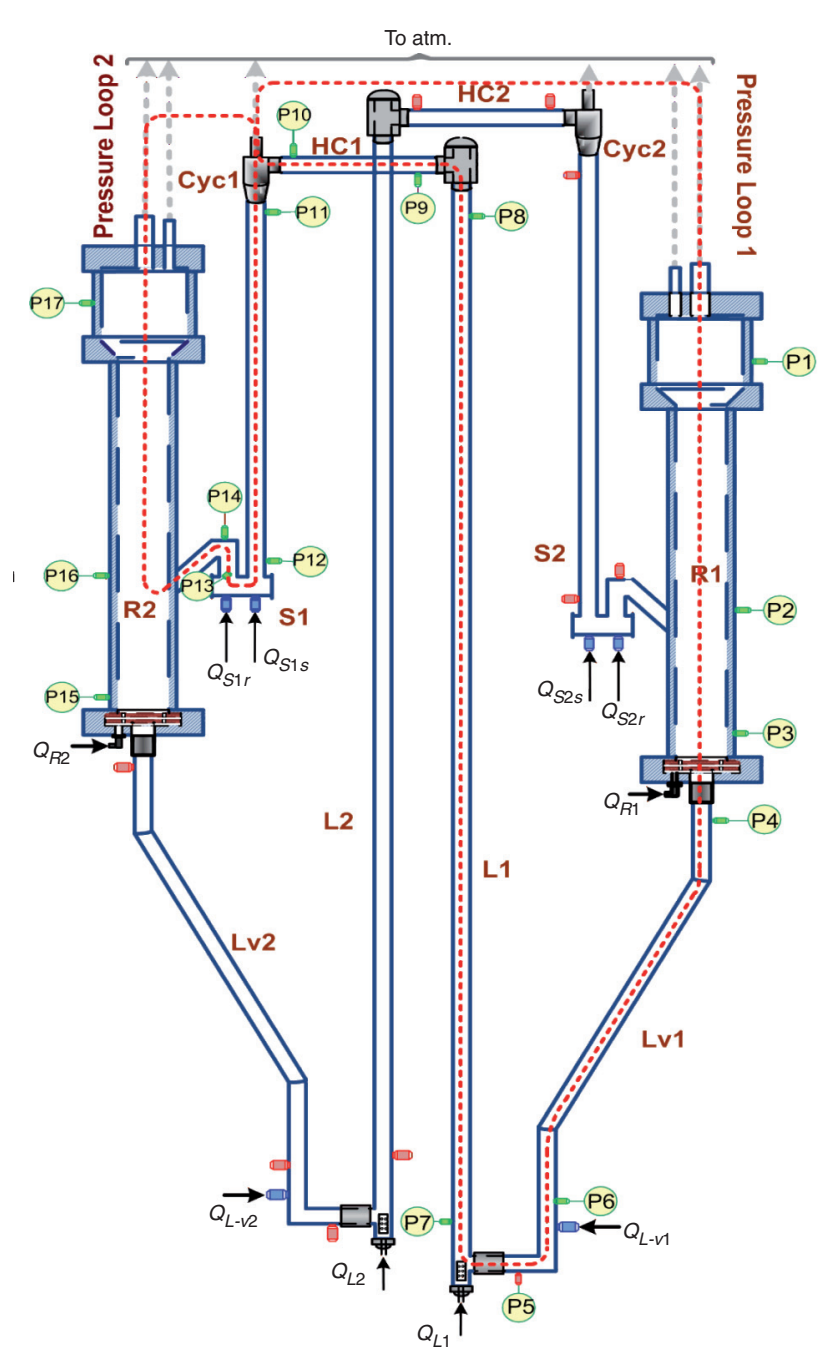

Figure 1

Scheme of the CLC cold flow prototype. Gas injection and pressure measurement taps are indicated. Two pressure loops for L-valve and Loop-seal are indicated in the scheme by red dashed line. Pressure taps used to measure pressure drop in each section correspondingly are listed in Table 1.

section of the L-valve in an acceptable range. L-valves are made of tubes with internal diameter of $0.017 \mathrm{~m}$. Solids at the exit of the L-valves are transported through a vertical riser $(0.021 \mathrm{~m} \mathrm{ID})$ followed by a horizontal conveying line. Solid-gas separation is performed in a cyclone where separated solids are led to a loop-seal located in the bottom of the cyclone dipleg. Loop-seals are used to ensure gas tightness between the Air Reactor and Fuel Reactor. Solid particles are then circulated back to the first reactor through an identical second circulation line.

Different designs are available for the loop-seal [20-22]. The configuration used in the current CLC installation is illustrated in Figure 2. The main elements of the loop-seal are the Supply Chamber (SC), which is the bottom section of the

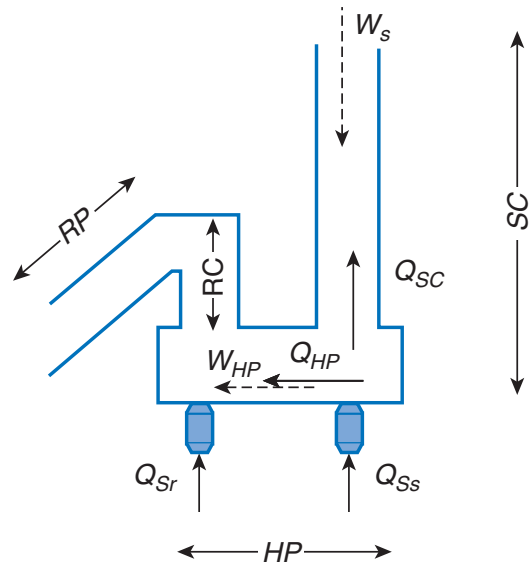

Figure 2

Loop seal configuration in the current design. Gas and solid flows are represented by solid and dashed arrows respectively.

cyclone dipleg, Horizontal Pipe (HP), Recycle Chamber (RC) and Recycle Pipe (RP). Two aerations exist in the loopseal, $Q_{S r}$ and $Q_{S s} \cdot Q_{S r}$ is to fluidize the solids in the RC and supply the minimum aeration required for the solids to flow into the reactor. $Q_{S s}$ is the critical aeration of the loop-seal, and serves two purposes: first, to convey the solids horizontally into the RC through the HP, and second, to facilitate the solid flow in the SC.

TABLE 1

Properties of sand particle used in the current study

\begin{tabular}{lcl}
\hline Property & Value & Measurement method \\
\hline$\rho_{s, \text { real }}\left(\mathrm{kg} / \mathrm{m}^{3}\right)$ & 2650 & Supplier data sheet \\
\hline$d_{\text {harmonic }}(\mu \mathrm{m})$ & 334 & Laser granulometry \\
\hline$d_{50}(\mu \mathrm{m})$ & 321 & Laser granulometry \\
\hline$U_{m f}(\mathrm{~m} / \mathrm{s})$ & 0.068 & Pressure drop variation method [32] \\
\hline$U_{t}(\mathrm{~m} / \mathrm{s})$ & 1.95 & Haider and Levenspiel [33] \\
\hline$\varepsilon_{m f}$ & 0.514 & Measured based on the expansion of solid bed \\
\hline$\varepsilon_{s}$ & 0.457 & $\begin{array}{l}\text { Volume of vibrated solid bed with determined } \\
\text { mass in a Graduated Cylinder }\end{array}$ \\
\hline$\varepsilon_{s t}$ & 0.404 & $\begin{array}{l}\text { Volume of vibrated solid bed with determined } \\
\text { mass in a Graduated Cylinder }\end{array}$ \\
\hline$\phi$ & 0.76 & Measured based on the Ergun equation [27] \\
\hline
\end{tabular}

\section{EXPERIMENTAL SETUPS}

Experiments were carried out in a cold flow prototype made with identical dimensions to the hot pilot plant. The installation was constructed with transparent Plexiglas ${ }^{\mathrm{TM}}$ 
TABLE 2

List of pressure drop variables and corresponding section in Figure 1

\begin{tabular}{c|l|c}
\hline Name & Section & $\begin{array}{c}\text { Reference } \\
\text { in Figure 1 }\end{array}$ \\
\hline$\Delta P_{R}$ & Reactor pressure drop & P3-P1 \\
\hline$\Delta P_{l v, v}$ & Vertical section of the L-valve & P6-P4 \\
\hline$\Delta P_{l v, H}$ & $\begin{array}{l}\text { Horizontal section of the L-valve and vertical } \\
\text { section below the aeration point }\end{array}$ & P6-P5 \\
\hline$\Delta P_{i n}$ & Riser solid inlet & P7-P5 \\
\hline$\Delta P_{L}$ & Riser pressure drop & P8-P7 \\
\hline$\Delta P_{T b}$ & T-Bend & P9-P8 \\
\hline$\Delta P_{H C}$ & Horizontal pneumatic conveying line & P10-P9 \\
\hline$\Delta P_{C y c, g}$ & Cyclone pressure drop for solid entrance and solid exit & P11-P10 \\
\hline$\Delta P_{C y c, g}$ & Cyclone pressure drop for gas entrance and gas exit & P10 \\
\hline$\Delta P_{S C}$ & Supply chamber of the loop seal & P12-P11 \\
\hline$\Delta P_{H P}$ & Horizontal pipe of the loop seal & P13-P12 \\
\hline$\Delta P_{R C}$ & Recycle chamber of the loop seal & P14-P13 \\
\hline$\Delta P_{R P}$ & Recycle pipe of the loop seal & P16-P14 \\
\hline$\Delta P_{D R}$ & $\begin{array}{l}\text { Pressure drop in the reactor above the loop seal } \\
\text { solid entrance point }\end{array}$ & P17-P16 \\
\hline & &
\end{tabular}

which helps visual observation during experimentation, and facilitates modifications if required.

Experiments were carried out in ambient temperature and pressure conditions using air as the fluidization gas. Sand particles were used with properties listed in Table 1. Fluidization air was supplied from a compressed air network with constant pressure. Gas inflow for L-valves and loop-seals was controlled using specific mass flow rate controllers connected to a computer for data collection. Gas flow into the risers and reactors was controlled with manual valves and flow rates were measured using rotameters with constant pressure. Pressure drops were measured by digital pressure transducers and were automatically registered on a computer with adjustable frequency. Several pressure taps were located all over the installation to investigate pressure drop in different sections of the circulation loop. Locations of pressure taps corresponding to each section of the system are illustrated in Figure 1 with corresponding abbreviations listed in Table 2 .

\section{EXPERIMENTAL PROCEDURES}

Solid flow rate measurement was carried out using batch solid flow between the reactors. Constant aeration was applied to the first L-valve (Lv1), while the other one was stopped and there was no recirculation solid flow. Solid was then continuously being transferred from reactor 1 (R1) into reactor 2 (R2), resulting in the reduction of the solid inventory in the R1 and increase in the solid inventory in the R2.
An instantaneous solid flow rate was determined using the slope of the curve representing the evolution of pressure drop along the fluidized bed which is proportional to bed height, as:

$$
W_{s}=\frac{d M_{s, R}}{d t}=\frac{A_{R}}{g} \cdot \frac{d P_{R}}{d t}
$$

Figure 3 illustrates an example of solid flow rate measurement for a L-valve flow rate of $Q_{l v}=0.29 \mathrm{Nm}^{3} / \mathrm{h}$.

Measuring the pressure drop for a section of riser in a fully developed flow regime provided a linear relationship between riser pressure drop and solid flow rate (Fig. 4) with air velocity being constant. This relationship can then be used to calculate solid flow rate during steady-state continuous operation.

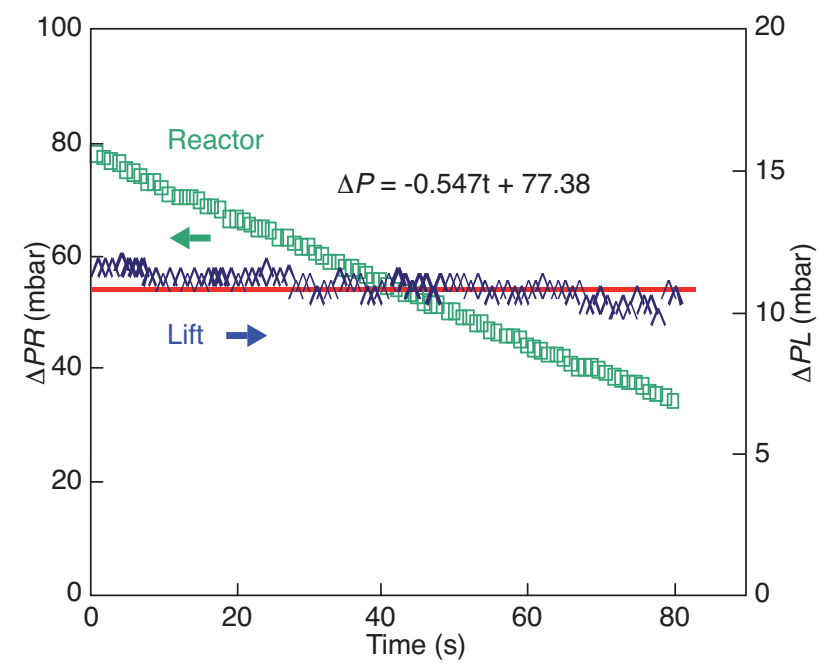

Figure 3

Pressure drop in reactor and riser for constant aeration in the L-valve for a batch process with $Q_{l v}=0.29 \mathrm{Nm}^{3} / \mathrm{h}$.

\section{RESULTS AND DISCUSSIONS}

\subsection{Solid Flow Control}

Control of solid flow rate is an important parameter in the Chemical Looping Combustion process. The solid circulation rate determines oxygen transport into the fuel reactor while playing an essential role in the thermal stability of the system. Moreover, the solid circulation rate has an important effect on the required solid inventory in the reactors to achieve optimum combustion efficiency. A decrease in the recirculation rate increases the minimum mass of solids needed in the system [23]. 


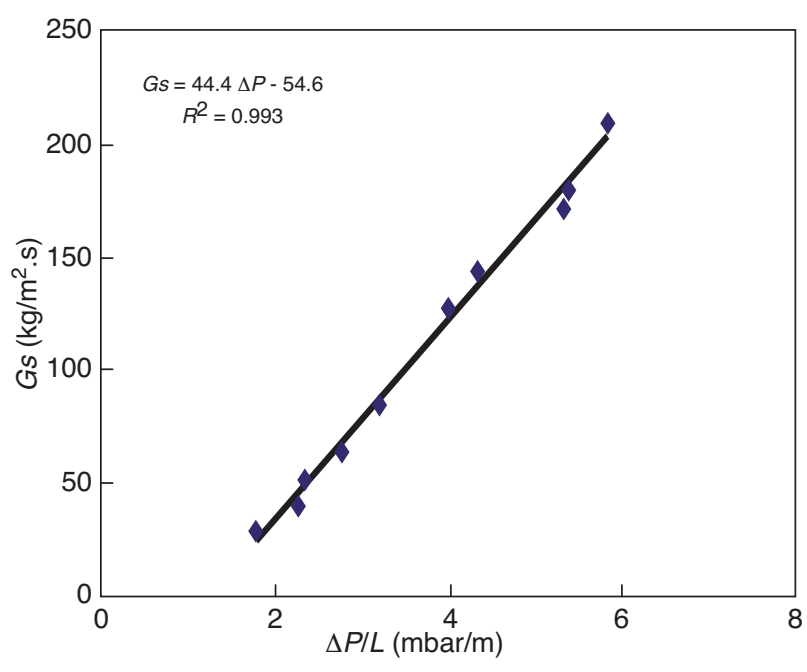

Figure 4

Solid flow rate versus pressure drop measured in the riser $U_{g, L}=6.8 \mathrm{~m} / \mathrm{s},(\Delta P=\mathrm{P} 8-\mathrm{P} 7$ in Fig. 1$)$.

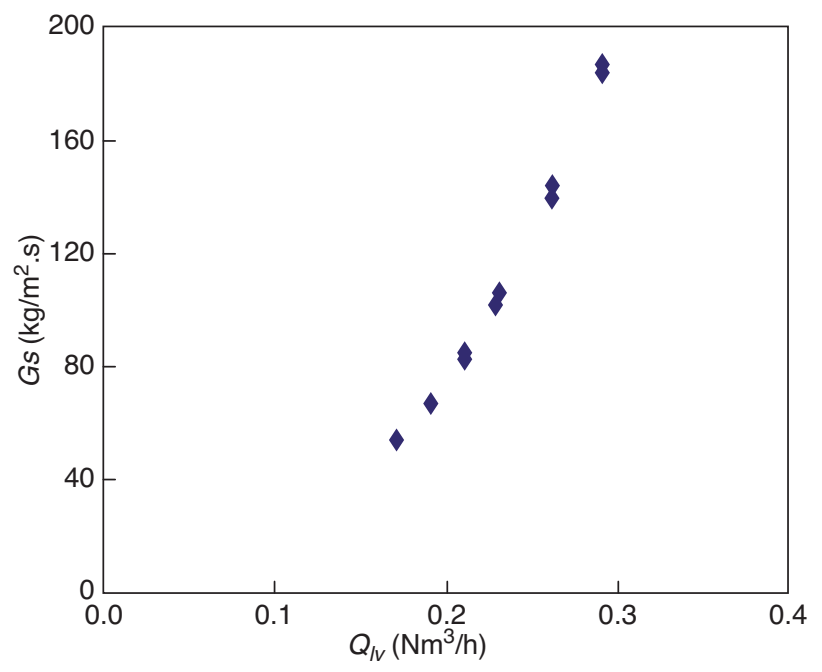

Figure 5

Solid circulation control achieved in the CLC circulation loop using L-valves, for a constant solid height of $0.5 \mathrm{~m}$ in the reactors.
L-valves were used in the current installation to control solid flow rate. The concept of L-valve operation has been discussed in the literature [24-26]. It is known that L-valves control solid flow based on the quantity of the gas passing through the horizontal section of the L-valve $\left(Q_{l v, H}\right)$ for Geldart group B particles. $Q_{l, H}$ depends on the aeration gas of the L-valve $\left(Q_{l v}\right)$ and on the gas flowing in the vertical section of the L-valve $\left(Q_{l v, v}\right)$, which is a function of the pressure balance across the solid circulation loop. Solid flux as a function of the aeration rate of the L-valve, with all other operating parameters being constant, is plotted in Figure 5. The results demonstrate that solid flux can be varied for a wide range of $50-180 \mathrm{~kg} / \mathrm{m}^{2}$.s with the aid of the L-valves. Moreover, even distribution of solid flux variation versus external L-valve aeration permits proper solid flow control through variation of $Q_{l v}$.

\subsection{Gas Leakage}

Solid circulation between the reactors could result in unflavored gas flow carried by solids. Gas leakage from the Air to the Fuel Reactor could result in dilution of the produced $\mathrm{CO}_{2}$ stream with Nitrogen. On the other hand, leakage from the fuel reactor reduces $\mathrm{CO}_{2}$ capture efficiency either with the combustion of leaked fuel in the AR or leakage of the produced $\mathrm{CO}_{2}$ out of the FR. In the current design gases could leave the reactor by solid flow through the L-valve either as interstitial gas trapped between particles or a gas flow due to high pressure developed in the bottom of the reactor. Gas leakage into the reactors could happen through two possibili- ties: either the gas carried by the solid flow into the reactor through the loop-seal, or the possible upward gas flow through the L-valve in the opposite direction from the solid flow. However, for gas leakage from one reactor to the other, the gas would leave the reactor through the L-valve, follow all the way along the riser, Horizontal Pipe and the cyclone and finally enter the second reactor through the loop-seal. Therefore, the possibility of gas leakage from one reactor to the other is greatly reduced in the current design due to the use of two dense solid flow elements in series, the L-valve and loop-seal, with addition of a dilution in between, the riser.

\subsection{L-valve Operation, Gas Leakage}

In the current CLC design, gas leakage out of the reactor could happen for the gases leaving the reactor with solid particles into the standpipe of the L-valve. The quantity of gas flow in this section is a function of the pressure drop across the element and the velocity of the solid particles (i.e. solid flow rate). Pressure drop in the standpipe of the L-valve varies to adjust the overall pressure balance over the solid circulation loop. The pressure balance loop considered for the L-valve is illustrated in Figure 1 as "pressure loop 1". The pressure loop is considered along the solid flow line starting from the atmospheric pressure at the exit of the reactor to the atmospheric pressure at the exit of the cyclone. Changes in pressure drop of the circulation loop elements affect the gas flow out of the reactor through the L-valve. Moreover, the gas flow in the standpipe affects the solid flow rate as it 


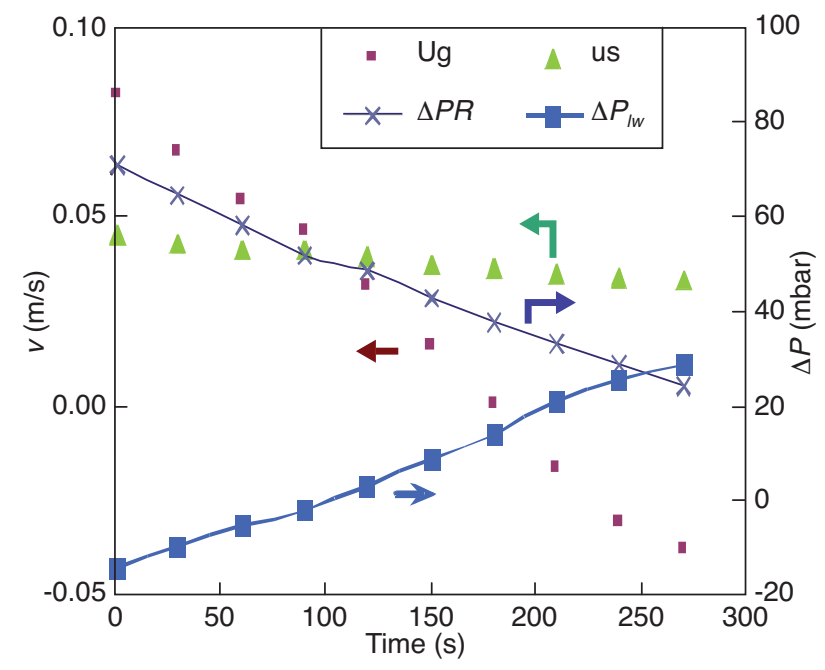

Figure 6

Variation of the pressure drop and velocities in the standpipe of the L-valve based on the variations of the pressure drop in the reactor for a batch solid circulation with $Q_{l v}=0.22 \mathrm{Nm}^{3} / \mathrm{h}$.

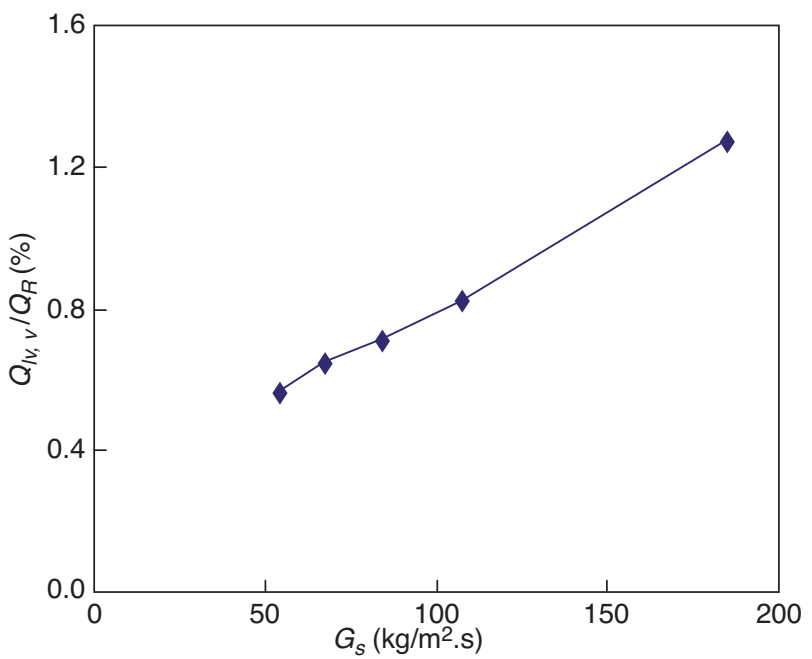

Figure 7

Evolution of gas leakage through the L-valve versus solid flux, expressed in the L-valve for a constant solid height of $0.5 \mathrm{~m}$ in the reactors. varies the quantity of gas passing through the horizontal section of the L-valve, which determines the solid flow rate. This phenomenon is illustrated in Figure 6, which presents an experiment where particles were transferred from R1 to R2 while R2 to R1 recirculation was stopped. Therefore, the solid inventory in the reactor R1 was continuously decreasing for a constant L-valve aeration flow rate, $Q_{l v}$. Reduction of pressure drop in the reactor due to the lower inventory increased the pressure drop of the standpipe of the L-valve. This demonstrates the dependence of the pressure drop across the standpipe of the L-valve on pressure drop along the solid circulation loop.

Pressure drop in the standpipe is formed by relative velocity of the gas and solid. The relative velocity can be calculated using Ergun's equation [27] for relative interstitial velocities $\left(\vec{v}_{r}=\vec{v}_{s}-\vec{v}_{g}\right)$ as in various published research [20, 28-31]:

$$
\frac{\Delta P}{L}=150 \cdot \frac{\mu_{f} v_{r}}{\left(\phi \cdot d_{p}\right)^{2}} \cdot \frac{(1-\varepsilon)^{2}}{\varepsilon^{2}}+1.75 \cdot \frac{\rho_{f} v_{r}{ }^{2}}{\phi \cdot d_{p}} \cdot \frac{(1-\varepsilon)}{\varepsilon}
$$

It should be noted that the superficial velocity $\left(U_{r}\right)$ is substituted by interstitial velocity $\left(v_{r}=U_{r} / \varepsilon\right)$ in this equation. Using this equation, calculated gas velocity evolution in the vertical arm of the L-valve is plotted in Figure 6. The solid velocity is calculated from Figure 4 for a measured pressure drop across the riser. The graph illustrates that for a constant aeration flow rate $\left(Q_{l v}\right)$, solid velocity varies due to the pressure drop variation over the circulation loop (variation imposed by the reduction of the pressure drop across the reactor).
Gas leakage through the L-valve could be assumed as being the ratio of the gas flow rate in the vertical arm of the L-valve divided by the fluidization rate of the reactor, $Q_{l v-v} / Q_{R}$. The gas leakage is plotted in Figure 7 for different solid fluxes in the L-valve. It shows that the leakage increases in a linear manner with solid flux. However, the value remains below $1.5 \%$ in the current case. Considering the equation of Ergun [27] as the governing equation in this flow, the effect of the solid and gas properties on gas leakage could be deduced. Accordingly, for a constant pressure drop and solid flow rate in the vertical arm, leakage increases by increase in voidage of the moving solid bed $(\varepsilon)$, solid particle diameter $\left(d_{P}\right)$, and sphericity of the particles $(\phi)$. And it could decrease by increase in gas viscosity $(\mu)$ and density $(\rho)$. A better understanding of the gas flow through the L-valve and loop-seal, however, would require a gas tracing study to quantify gas leakage directly as a function of operating parameters. This study will be conducted in the near future to confirm the conclusions of the present study based on pressure drop measurements.

\subsection{Loop-Seal Operation, Leakage Control}

Solid flow into the reactors could carry gases into the bed, resulting in gas leakage. To minimize this possibility, loopseals are employed at the solid entrance into the reactor (Fig. 1). Loop-seals are commonly used in the Circulating Fluidized Beds to ensure gas tightness of the solid flow into a riser and to prevent direct gas flow out of the reactor (usually into the dipleg of a cyclone) $[20,28]$. In the current design, 
loop-seals are used for solid flow into the dense phase of the bubbling fluidized bed. Accordingly, the solid height in the reactor considerably affects the operation of the loop-seal through the imposed back pressure on the loop-seal. Gas tightness in the loop-seal is achieved by the positive pressure drop developed across the moving dense phase solid column formed in the Supply Chamber (P12-P11 in Fig. 1). This prevents free gas flow in or out of the reactor along the solid transport line.

There are geometrical and operational similarities between the L-valve and the loop-seal. In both elements pressure drop of the moving bed in standpipes (SC in the loop-seal) is developed due to the relative solid and gas flows and is a function of the overall pressure balance. In the L-valve, however, solid flow rate varies as a function of the aeration gas while the bed level in the standpipe remains constant. In the loop-seal, solid flow rate is constant while the height of the moving solid column varies.

Formation of the solid column in the Supply Chamber of the loop-seal was demonstrated to be mainly a function of the loop-seal pressure balance, loop-seal aeration in $Q_{S S}$ and solid flow rate.

The relevant pressure balance to consider for the loopseal in the present case is the pressure difference between the cyclone atmospheric gas discharge and the atmospheric discharge of the reactor. This pressure loop is illustrated in Figure 1 by a closed red line named "pressure loop 2". The Supply Chamber of the loop-seal is a non-fluidized standpipe, the pressure drop of which depends on the pressure drop across the other elements of the system. $\Delta P_{S C}$ varies to adjust the overall pressure balance in the circulation loop. This phenomenon is well demonstrated in Figure 8, where solids are circulated in batch operation with constant flow rate from R1 to R2. Pressure drop in the reactor $\left(\Delta P_{\mathrm{R} 2}\right)$ was then continuously increasing. Therefore, pressure drop in the standpipe follows the pressure variation imposed by the reactor pressure drop $\left(\Delta P_{\mathrm{R} 2}\right)$. Pressure drops in the other elements of the loopseal remain constant regardless of the variation in the pressure drop across the reactor. Therefore, pressure drops in these elements were concluded to be mainly a function of the solid flow rate. Moreover, it was revealed that it is necessary to build up a minimum pressure drop at the loopseal outlet by increasing bed level above the loop-seal discharge point in the bed. This is required to provide a stable operation in the loop-seal with a dense phase buildup in the SC.

The height of the solid column in the Supply Chamber also depends on the aeration rate into the element, through the relative gas-solid velocity. This is illustrated in Figure 9, where for a constant solid flow rate and pressure drop in the reactor, solid height in the Supply Chamber $\left(L_{S C}\right)$ decreases when $Q_{S s}$ increases. Gas flow rate in the Supply Chamber can be calculated using a modified equation of Ergun for interstitial relative gas-solid velocities, similar to the procedure explained for the L-valve. A simple material balance at the aeration point of $Q_{S S}$ in the loop-seal gives:

$$
Q_{H P}=Q_{S s}+Q_{S C}
$$

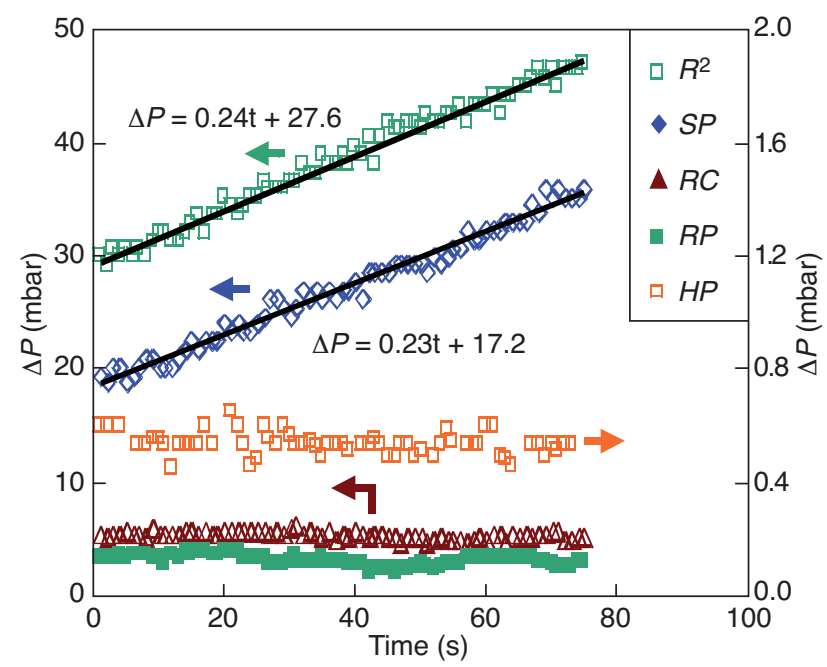

Figure 8

Evolution of pressure drop in the loop-seal components for a batch process with $G_{s}=86 \mathrm{~kg} / \mathrm{m}^{2}$.s and $Q_{S s}=0.21 \mathrm{Nm}^{3} / \mathrm{h}$.

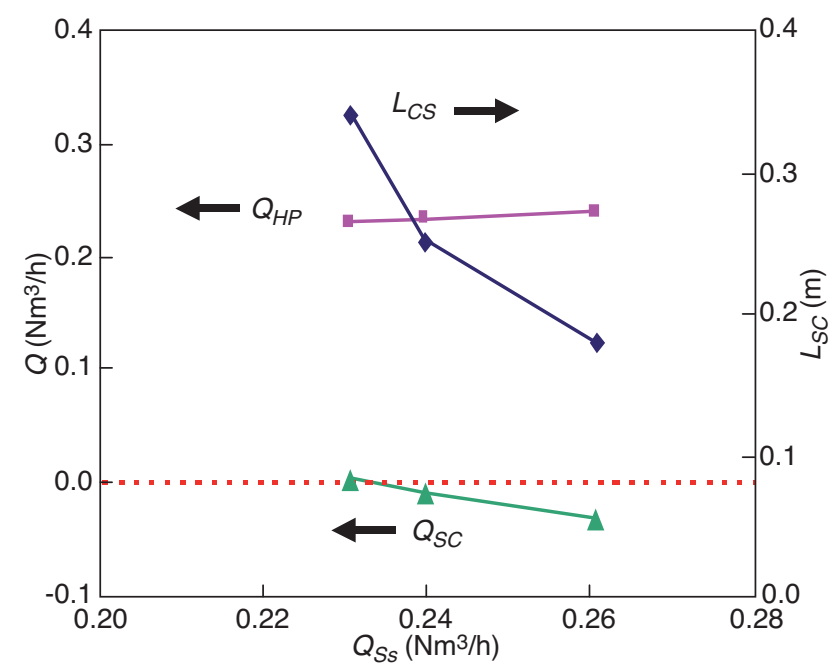

Figure 9

Effect of the loop seal aeration for $145 \mathrm{~kg} / \mathrm{m}^{2} . \mathrm{s}$ and $\Delta P_{S C}=$ $18.3 \mathrm{mbar}$, positive sense is direction of solid flow. 
The experimental results (Fig. 9) demonstrate that for a fixed solid flow rate, and an external injected gas in $Q_{S s}$, gas flow in the Horizontal Pipe $\left(Q_{H P}\right)$ remains fairly constant. Accordingly, for a constant solid flow rate two cases are possible based on the variation of the external loop-seal aeration in $Q_{S s}$ :

- if $Q_{S S}<Q_{H P}$; the deficient gas flow required for horizontal solid flow, $Q_{H P}-Q_{S S}$, will be supplied from the gases carried down by the solid flow. $Q_{S C}$ will have a positive sign and gases leak into the reactor with solid flow;

- if $Q_{S s}>Q_{H P}$; surplus of the aeration gas, $Q_{S s}-Q_{H P}$, flows into the $S C . Q_{S C}$ will then be negative. Therefore, gas flow in the Supply Chamber is upwards and the best gas tightness is achieved.

This phenomenon is well illustrated in Figure 9, where $Q_{S C}$ varies from +0.003 to $-0.03 \mathrm{~nm}^{3} / \mathrm{h}$ due to increase in the $Q_{S s}$ for a constant solid flow rate. However, positive values of $Q_{S s}$ result in gases carried by the solids, i.e. leakage into the reactor. Accordingly, the best gas tightness is achieved once $Q_{S s} \geq Q_{H P}$. The gas flow in the Supply Chamber is, however, limited to the fluidization of the solid column, which happens once $v_{r}>v_{m f}$ where $v_{m f}=U_{m f} / \varepsilon_{m f}$. Besides, maximum gas tightness is achieved once $v_{g} \leq 0$ (as $\left.Q_{S C} \leq 0\right)$. Considering the condition of $v_{g}=0$ as minimum gas velocity for a gastight condition, relative velocity reduces to its minimum value for a gastight condition as: $v_{r, \min }=v_{s}$. This indicates a condition that there is no gas flow upwards or downwards in the SC. Therefore, loop-seal operation in a gastight non-fluidized case is limited to $v_{s}=v_{r} \leq v_{m f}$ which results in a limit of $170 \mathrm{~kg} / \mathrm{m}^{2} . \mathrm{s}$ for the current solid.

It should be noted that the loop-seal can have a stable operation even if the Supply Chamber is fluidized. This, however, reduces the flexibility of the loop-seal operation. As mentioned above, the Supply Chamber in the loop-seal absorbs the extra pressure drop across the circulation loop to adjust the overall pressure balance. Pressure variation in the loop-seal is done through two mechanisms: variation of the height of the solid column and variation of the relative solidgas velocity, which varies the pressure drop along the unit length of the element $\left(\Delta P_{S C} L\right)$. In the case of the fluidized element, pressure absorption through the relative solid gas velocity is no longer available as it does not change the pressure drop in a fluidized bed. Therefore, pressure drop variation can just be carried out by the variation of the height of the solid bed. This should be controlled cautiously, as solid can fill up the Supply Chamber and enter into the cyclone. This will then abrupt the cyclone operation and result in system instability. In this case, solids could leave the system through the gas outlet of the cyclone. Moreover, upward gas flow in the loop-seal toward the cyclone should be minimized. It was observed that high upward gas flow into the cyclone can result in the instability of the cyclone operation and cause solid to be lost through the gas exit of the cyclone

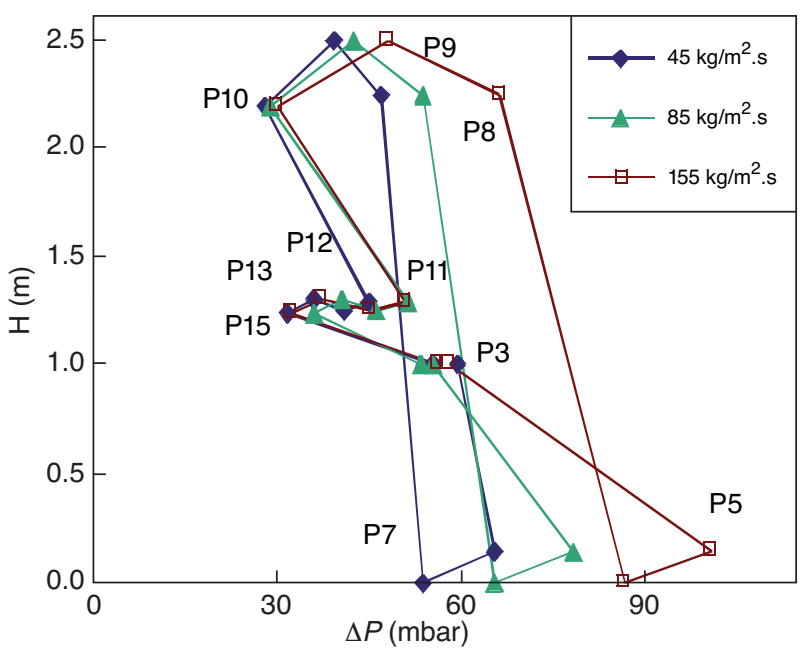

Figure 10

Pressure drop variation along the solid circulation loop for different heights in the reactor for different solid fluxes of 45 , 85 and $151 \mathrm{~kg} / \mathrm{m}^{2} . s$. Indicated pressures refer to the pressure tabs noted in Figure 1.

out of the system. Stability of the loop-seal operation has been discussed in Circulating Fluidized Bed systems by different authors [20, 28, 29].

\subsection{Steady-State Operation}

Continuous steady-state operations were successfully carried out in the cold prototype. The system demonstrated stable operation where pressure drops and solid inventories in the reactors remained constant in the course of the operation. In a stable solid circulation operation, pressure variation is balanced over the circulation loop. For the current CLC solid circulation loop this can be written as:

$$
\begin{gathered}
\Sigma \Delta P=\Delta P_{R 1}+\Delta P_{l v, v}+\Delta P_{l v, H}+\Delta P_{L}+\Delta P_{T b}+\Delta P_{H C}+ \\
\Delta P_{C y s, s}+\Delta P_{S C}+\Delta P_{H P}+\Delta P_{R C}+\Delta P_{R P}+\Delta P_{D R 2}=0
\end{gathered}
$$

where $\Delta P$ is positive if pressure increases along the element and is negative if pressure decreases along the element. The evolution of pressure drop in the system is well demonstrated in Figure 10 for three different solid flow rates. As illustrated in the graph, higher solid flow rate increases the pressure drop across the vertical section of the L-valve (P3-P5). However, this is due to the increase in pressure drop across other system elements including the riser, horizontal section and the cyclone, while pressure drop across the reactor remains constant. This illustrates well the behavior of the vertical section of the L-valve in absorbing the developed pressure drop across the solid circulation loop. A similar phenomenon can be observed for the Supply Chamber of the 
loop-seal (P10-P11), where the pressure drop increases across the element for higher solid flow rates. The reason for this behavior is similar to the L-valve, as the Supply Chamber absorbs the extra pressure drop across the solid circulation loop to adjust the overall pressure balance.

\section{CONCLUSION}

A novel Chemical Looping Combustion configuration was introduced in this paper. Experimental results from operation of a $10 \mathrm{~kW}_{\text {th }}$ equivalent cold prototype were presented. Independent solid circulation control was achieved by use of non-mechanical L-valves, resulting in a wide range of solid flux control of $50-180 \mathrm{~kg} / \mathrm{m}^{2}$.s. Gas leakages in the L-valve and the loop-seal were studied. The results demonstrated that proper gas tightness can be achieved in the system through optimized control of operating conditions, mostly aeration rate in the loop-seal and pressure drop across the standpipe of the L-valve. Steady-state solid circulation was achieved in the system with a constant pressure drop across the system elements, demonstrating the stability of the solid circulation in the current configuration.

\section{REFERENCES}

1 Metz B., Davidson O., de Coninck H., Loos M., Meyer L. (2005) IPCC Special Report on Carbon Dioxide Capture and Storage, Cambridge University Press, Cambridge.

2 Damen K., van Troost M., Faaij A., Turkenburg W. (2006) A comparison of electricity and hydrogen production systems with $\mathrm{CO}_{2}$ capture and storage. Part A: Review and selection of promising conversion and capture technologies, Prog. Energ. Combust. 32, 2, 215-246.

3 Hossain M.M., de Lasa H.I. (2008) Chemical-looping combustion (CLC) for inherent $\mathrm{CO}_{2}$ separations - a review, Chem. Eng. Sci. 63, 4433-4451.

4 Richter H.J., Knoche K. (1983) Efficiency and costing, Second law analysis of processes, ACS symposium series $\mathbf{2 3 5}$, Washington DC.

5 Forero C.R., Gayán P., de Diego L.F., Abad A., García-Labiano F., .Adánez J. (2009) Syngas combustion in a $500 \mathrm{Wth}$ ChemicalLooping Combustion system using an impregnated $\mathrm{Cu}$-based oxygen carrier, Fuel Process. Technol.90, 12, 1471-1779.

6 de Diego L.F., García-Labiano F., Gayan P., Celaya J., Palacios J.M., Adanez J. (2007) Operation of a 10 kWth chemical-looping combustor during $200 \mathrm{~h}$ with a $\mathrm{CuO} \cdot \mathrm{Al}_{2} \mathrm{O}_{3}$ oxygen carrier, Fuel 86, 1036-1045.

7 Kolbitsch P., Pröll T., Bolhar-Nordenkampf J., Hofbauer H. (2009) Design of a Chemical Looping Combustor using a Dual Circulating Fluidized Bed Reactor System, Chem. Eng. Technol. 32, 3, 398-403.

8 Kronberger B., Johansson E., Löffler G., Mattisson T., Lyngfelt A., Hofbauer H. (2004) A Two-Compartment Fluidized Bed Reactor for $\mathrm{CO}_{2}$ Capture by Chemical-Looping Combustion, Chem. Eng. Technol. 27, 12, 1318-1326.
9 Real Son Sung, Kim Sang Done, Lee Jea-Keun (2007) 2007 ECI Conference on the 12th International Conference on Fluidization - New Horizons in Fluidization Engineering, Vancouver, Canada.

10 Andrus H.E., Chiu J.H., Thibeault P.R., Brautsch A. (2009) The 34th International Technical Conference on Clean Coal \& Fuel Systems, Clearwater, Florida, USA.

11 Noorman S., van Sint Annaland M., Kuipers H. (2009) Packed Bed Reactor Technology for Chemical-Looping Combustion, Ind. Eng. Chem. Res. 46, 12, 4212-4220.

12 Noorman S. (2007) International Oxy-Combustion Research Network, Windsor, CT, USA.

13 Dahl Ivar M., Bakken E., Larring Y., Spjelkavik Aud I., Håkonsen Silje F., Blom R. (2009) On the development of novel reactor concepts for chemical looping combustion, Energy Procedia 1, 1513-1519.

14 Lyngfelt A., Thunman H. (2005) Construction and $100 \mathrm{~h}$ of Operational Experience of A $10-\mathrm{kW}$ Chemical Looping Combustor, in Carbon Dioxide Capture for Storage in Deep Geologic Formations, Thomas D.C., Benson S.M. (eds), Elsevier Ltd.

15 Ryu H.J., Jin G.T., Yi C.K. (2005) Demonstration of Inherent $\mathrm{CO}_{2}$ Separation and No NOx Emission in a $50 \mathrm{~kW}$ ChemicalLooping Combustor: Continuous Reduction and Oxidation Experiment, in Morris T., Gale J., Thambimuthu K. (eds), Elsevier Ltd.

16 Shen Laihong, Wu Jiahua, Gao Zhengping, Xiao Jun (2009) Reactivity deterioration of $\mathrm{NiO} / \mathrm{Al}_{2} \mathrm{O}_{3}$ oxygen carrier for chemical looping combustion of coal in a $10 \mathrm{kWth}$ reactor, Combust. Flame.

17 Pröll T., Rupanovits K., Kolbitsch P., Bolhàr-Nordenkampf J., Hofbauer H. (2009) Cold Flow Model Study on a Dual Circulating Fluidized Bed System for Chemical Looping Processes, Chem. Eng. Technol. 32, 3, 418-427.

18 Kronberger B., Lyngfelt A., Lolffler G., Hofbauer H. (2005) Design and Fluid Dynamic Analysis of a Bench-Scale Combustion System with $\mathrm{CO}_{2}$ Separation-Chemical-Looping Combustion, Ind. Eng. Chem. Res. 44, 546-556.

19 Gauthier T., Bayle J., Leroy P. (2000) FCC: Fluidization Phenomena and Technologies, Oil Gas Sci. Technol. - Rev. IFP 55, 2, 187-207.

20 Basu P., Butler J. (2009) Studies on the operation of loop-seal in circulating fluidized bed boilers, Appl. Energ. 86, 1723-1731.

21 Basu P. (2006) Combustion and Gasification in Fluidized Beds, CRC Press, Taylor \& Francis Group, Boca Raton.

22 Butler J.W., Basu P. (2007) 2007 ECI Conference on the 12th International Conference on Fluidization - New Horizons in Fluidization Engineering, Vancouver, Canada.

23 Gayan P., Abad A., Adanez J., de Diego L.F., García-Labiano F. (2004) Reduction and oxidation kinetics of a copper-based oxygen carrier prepared by impregnation for chemical-looping combustion, Ind. Eng. Chem. Res. 43, 8168-8177.

24 Geldart D., Jones P. (1991) The behaviour of L-valve with granular solids, Powder Technol. 67, 163.

25 Knowlton T.M., Hirsan I. (1997) Ninth Synthetic Pipeline Gas Symposium, Chicago, Illinois.

26 Smolders K., Baeyens J. (1995) The Operation of L-valve to Control Standpipe Flow, Adv. Powder Technol. 6, 03, 163.

27 Ergun S. (1952) Fluid flow through packed columns, Chem. Eng. Process. 48, 2, 89.

28 Basu P., Chen L. (2000) An Analysis of Loop Seal Operations in a Circulating Fluidized Bed, Trans IChemE 78, Part A. 
29 Cheng L., Basu P. (1999) Effect of pressure on loop seal operation for a pressurized circulating fluidized bed, Powder Technol. 103, 203-211.

30 Kim S.W., Namkung W., Kim S.D. (1999) Solid Flow Characteristics in Loop-Seal of a Circulating Fluidized Bed, Korean J. Chem. Eng. 16, 1, 82-88.

31 Kim S.W., Kim S.D. (2002) Effects of particle properties on solids recycle in loop-seal of a circulating fluidized bed, Powder Technol. 124, 76-84.
32 Kunii D., Levenspiel O. (1991) Fluidization Engineering, 2nd edition, Butterworth-Heinemann, Boston, US.

33 Haider A., Levenspiel O. (1989) Drag coefficient and terminal velocity of spherical and non spherical particles, Powder Technol. 58, 1, 63-70.

Final manuscript received in September 2010

Published online in April 2011 